\title{
EVOLUTION IN CLOSELY ADJACENT PLANT POPULATIONS \\ VI. MANIFOLD EFFECTS OF GENE FLOW
}

\author{
JANIS ANTONOVICS* \\ School of Plant Biology, University College of North Wales, Bangor
}

Received 10.ix.67

\section{INTRODUGTION}

RECENTLY there has been a growing interest in evolution in heterogeneous environments. It has been realised that a uniform environment is an abstract concept with little basis in natural situations. Environmental heterogeneity can have many evolutionary consequences depending on factors too diverse to review here (see Levins, 1965; Bradshaw, 1965). One type of heterogeneity which is important is local differentiation between habitats. This produces forces promoting population differentiation by selection for adaptation to local conditions. At the same time, assuming the heterogeneity is reasonably small scale, there will be gene flow between contrasting populations tending to counteract the forces of local adaptation. Previous papers in this series (Jain and Bradshaw, 1966; McNeilly, 1967) have emphasised the importance of the interplay between gene flow and selection in determining patterns of differentiation between adjacent populations.

However, none of this work has considered the effects of continued gene flow on the genetic structure of a single population. Whereas many papers have considered the " influx" of new genes through mutation, very few have considered the influx of new genes from adjacent populations. The aim of this paper is therefore to describe the effects of gene flow on a population using a computer simulation.

\section{The BASIC MODEL}

A fairly detailed account of the model is necessary, since the conclusions to be drawn from a theoretical investigation depend on the premises on which it is based. A brief account of part of this model has already been given (Antonovics, 1967a).

The model was that of a single infinitely large random breeding population consisting of the genotypes $A A, A a$, and $a a$. Various factors were then allowed to operate.

\section{Selection}

At each generation selection operated against the a genotype.

\section{Gene flow}

Gene flow was imposed by addition of a frequency, $g$, of incoming male genotypes. Two types of gene flow were distinguished:

(a) Pollen flow. Selection occurred after the incoming genotypes had mated with the remainder of the population.

* Present address: Department of Biology, The University, Stirling. 


$$
A A \quad A a \quad a a \quad a a \text { (incoming) }
$$

Genotype frequency:

$\begin{array}{lcccc}\text { Males } & (1-g) u & (1-g) v & (1-g) w & g \\ \text { Females } & u & v & w & \end{array}$

Males and females in these frequencies then mated at random and selection was imposed on the products of mating.

(b) Seed flow. Selection occurred both on the pre-existing population and on the incoming genotypes before they mated. Here the extra genotypes did not enter the mating scheme till the genotype frequencies for the next generation had been calculated. Then the genotype frequencies become:

$a a$

New genotype: frequency

$$
(1-g) u \quad(1-g) v \quad(1-g) w+g
$$

\section{Changing gene flow}

It has been stressed in previous papers in this series (McNeilly and Antonovics, 1967; Antonovics, 1967a) that in the early stages of colonisation the density of individuals in an area will be low and therefore the gene flow from outside high. As colonisation proceeds, the density will increase and gene flow will therefore decrease. To investigate the genetic changes that are likely to occur during early colonisation, a model of changing gene flow was developed. It seemed reasonable to assume that the decrease of gene flow is proportional to the increase in population numbers. The formula for population increase under "limited resources" was therefore modified to give a corresponding decrease in gene flow:

$$
\mathcal{N}=(1-g)\left[1-\frac{1}{1+\exp (n-r t)}\right]+g
$$

where $\mathcal{N}=$ gene flow at a particular generation, $t$,

$g=$ final gene flow,

$n=$ constant to determine initial amount of gene flow,

$r=$ constant to determine rate of decrease of gene flow,

$t=$ generation.

This equation gave a sigmoid curve, decreasing from an initially high value to a final low value, and so represented decreasing gene flow with increasing colonisation.

\section{Perenniality}

This feature was imposed on the population by adding the parental genotypes (i.e. the previous generation) to the genotypes produced by those parents and gene flow from outside (i.e. the next generation). The parental genotypes were added in equal (overall) frequency to the offspring genotypes, and the total population then subjected to selection.

The model was therefore of a population where the individuals had an indefinite life-span except that a certain proportion were culled by selection at each generation. The selection pressure acted on the established parents in the same way as on the offspring of a particular generation. The addition of parental genotypes in equal (overall) frequency to offspring genotypes represented a rather extreme case since very rarely does the number of 
offspring equal the number of parents. Increasing the contribution from the offspring reduced the effects of perenniality but did not otherwise materially affect the results.

5. Self-fertility

The results of this aspect of the model have already been described (Antonovics, 1967a) and will only be considered briefly here.

The recurrence equations incorporating these features are given by Antonovics (1967a).

\section{The EFFEgTs OF GENE FLOW}

(a) Pollen flow

If pollen flow is the only influence on the population, then the incoming type, $a a$, rapidly spreads through the population. However, if there is selection against $a a$, the result will depend on the selection pressure, the pollen flow, and on the degree of dominance of $A / a$. The following points emerge:

(i) Pollen flow is remarkably effective in maintaining a gene in a population in spite of strong selection against it (fig. 1). For example, if the favoured gene is dominant, only 0.1 pollen flow will reduce the frequency of the favoured gene from 1.0 to 0.68 when the selection against the incoming gene is 0.4 .

(ii) Pollen flow is remarkably effective in maintaining heterozygosity (fig. 1). If the favoured gene shows no dominance or is dominant, then there is an excess of heterozygotes over random expectation. Looking at genotype frequencies alone, it gives the erroneous impression that there is selection favouring heterozygotes.

(iii) The rate of change of gene frequency shows a rapid change in the initial stages followed by a slowing down as equilibrium is approached.

(iv) The number of generations to reach equilibrium (determined as the point when gene frequency did not change by more than 0.000001 between generations) follows a complex pattern depending on selection, pollen flow and dominance. Two main points emerge (table 1). Firstly, the time taken to reach equilibrium does not depend greatly on the initial gene frequency. Secondly, when the favoured gene is dominant, the time taken to reach equilibrium is less when there is pollen flow. This is because with pollen flow equilibrium is reached before the unfavoured recessive gene has been completely eliminated. When the favoured gene is not dominant or is recessive, the time taken to reach equilibrium is greater with pollen flow.

\section{(b) Seed flow}

The effects of seed flow were investigated only briefly since seed flow did not seem as important as pollen flow in plant populations. Seed flow has less effect than pollen flow under high selection intensities since nearly all the incoming genotypes are killed before they mate, but at lower selection intensities the opposite is true (fig. 2). Seed flow has no effect on heterozygote frequency since the addition of extra genotypes occurs before selection and random mating.

\section{(c) Changing pollen flow}

Changing gene flow was only investigated in the case of pollen flow. $2 \mathrm{~L}$ 

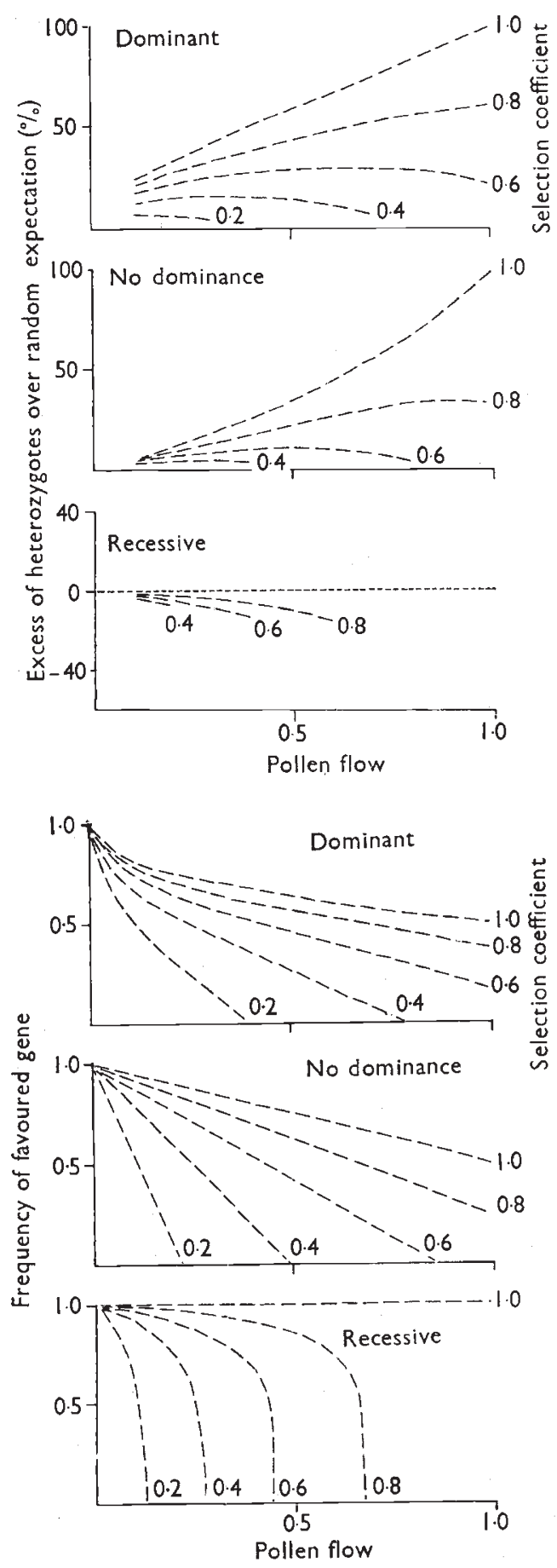

Fig. 1.-Effect of selection and pollen flow on gene frequency and heterozygosity at equilibrium. (Selection coefficients, and degree of dominance of favoured gene, are indicated on graphs.) 

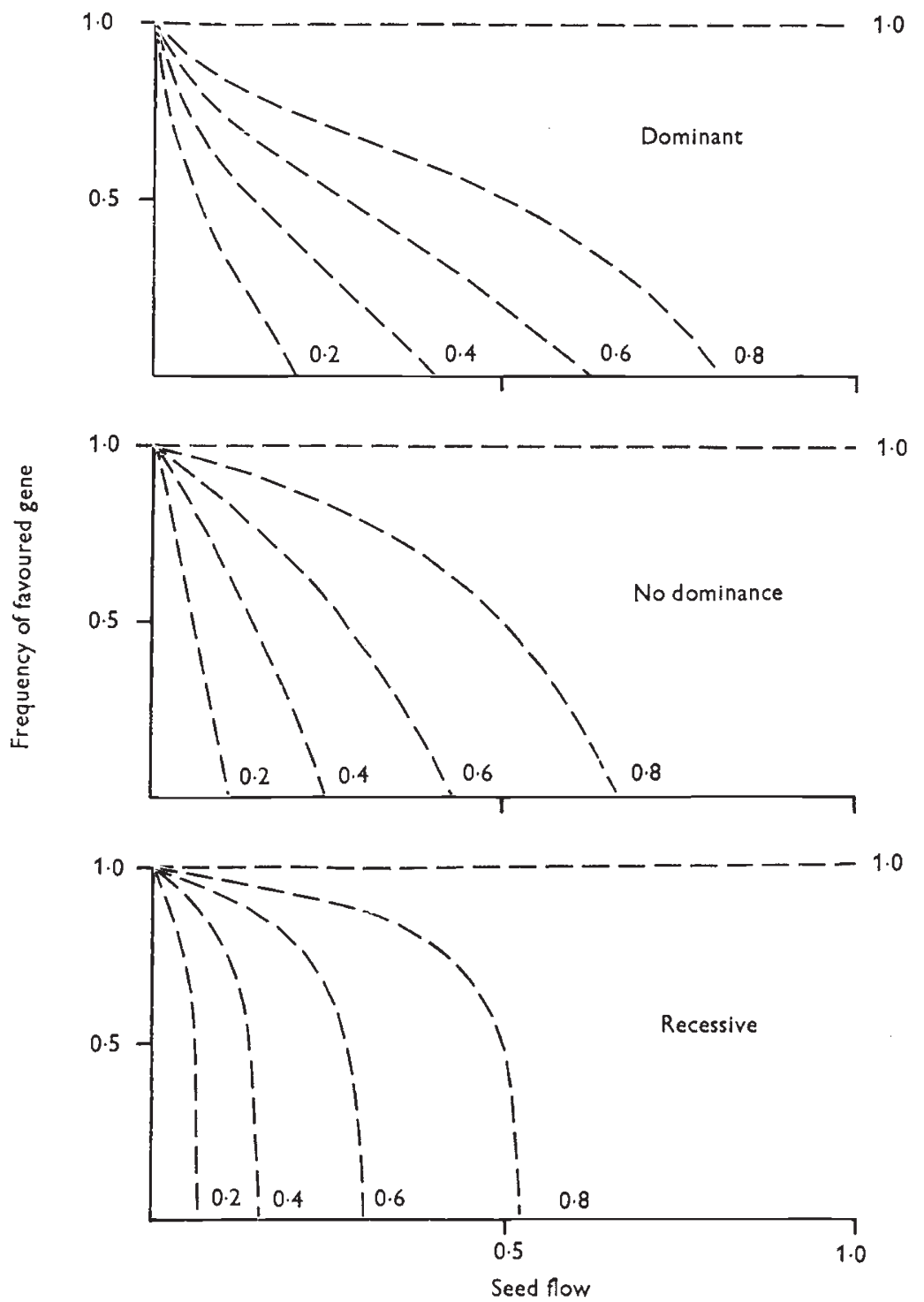

FIG. 2.-Effect of selection and pollen flow on gene frequency at equilibrium. (Select ion coefficients, and degree of dominance of favoured gene, are indicated on graphs.)

The initial phase of intense pollen flow during colonisation can have serious consequences for the population. The level to which the frequency of the favoured gene is lowered during this initial phase depends on the speed of colonisation (fig. 3). If colonisation is slow, then the effects of pollen flow are more serious. The frequency reached by the favoured gene depends also on the selection pressure against the incoming type (fig. 3), but the initial gene frequency has very little effect on the results. 

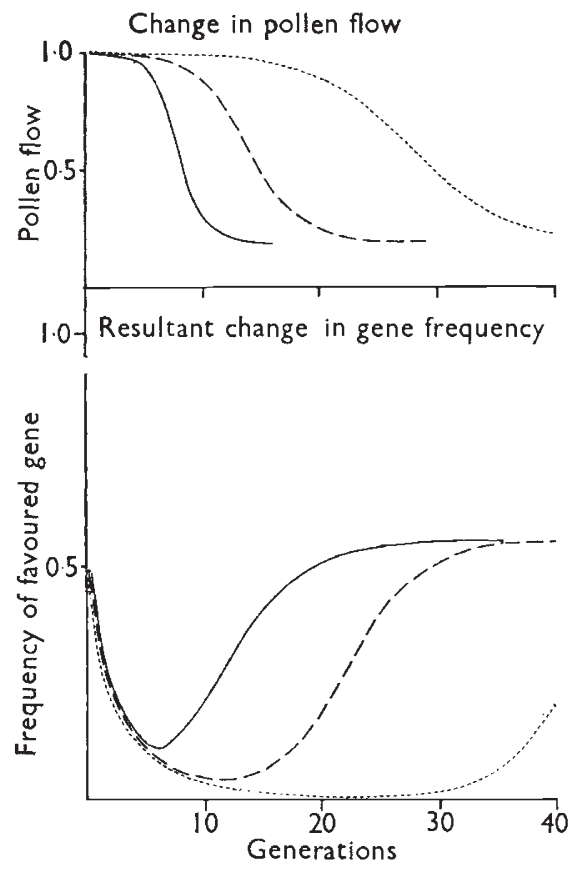

Change in pollen flow

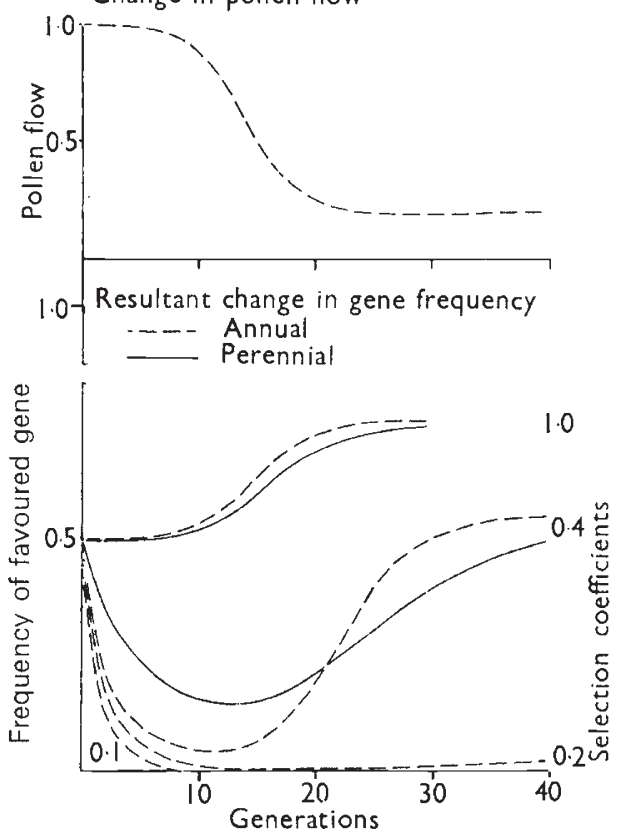

FIG. 3.-Effect of changing pollen flow on gene frequency. (Selection coefficients are indicated on graphs, favoured gene is dominant.)

The high initial pollen flow produces a very high degree of heterozygosity (fig. 4). With very strong selection pressures the initial colonisers are likely to be all heterozygotes. 

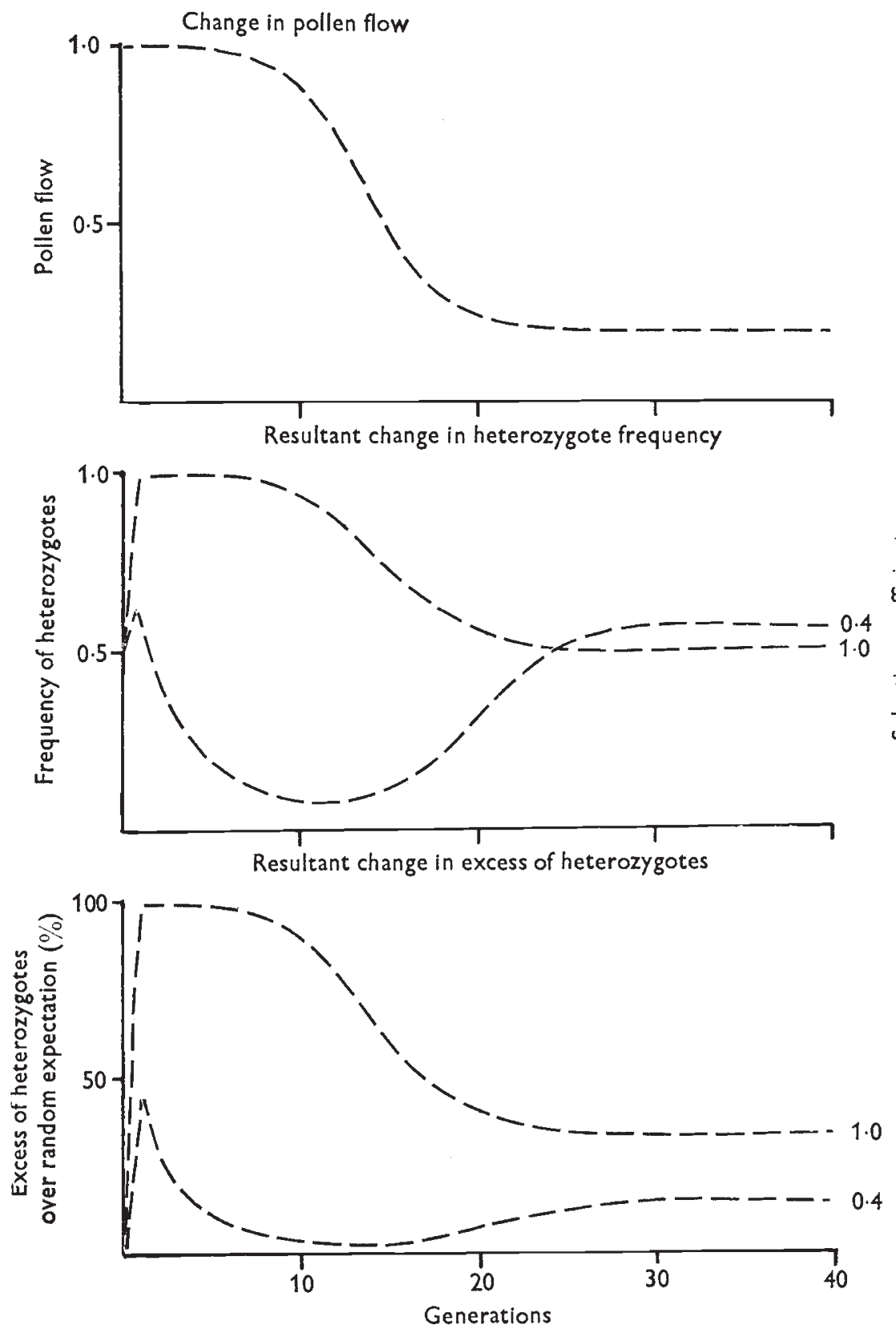

Fig. 4.-Effect of changing pollen flow on heterozygosity. (Selection coefficients are indicated on graphs, favoured gene is dominant, initial gene frequency $=0.5$.)

\section{(d) Perenniality}

Perennial populations change more slowly than annual populations but the final equilibrium frequencies are the same in both (fig. 5). The slower 
genetic response of a perennial population can have interesting genetic consequences. Firstly, since adaptation is slower it implies that the genetic load in a perennial population is greater over a period of time than in an annual. However, it may also mean that, in the initial stages of colonisation when gene flow is high, the perennial suffers a far lower reduction of the favoured gene (fig. 3). Secondly, the lag of the perennial population is reflected in the genotype frequencies. For example (fig. 5), if at the beginning the number of heterozygotes is below the equilibrium frequency, then the number increases more slowly in a perennial. The converse is true if there is initially a high frequency: the perennial population is more heterozygous than the annual.

(a) Effect of perenniality on gene frequency (pollen flow $=0.2$, selection coefficient $=1 \cdot 0$, favoured gene dominant).

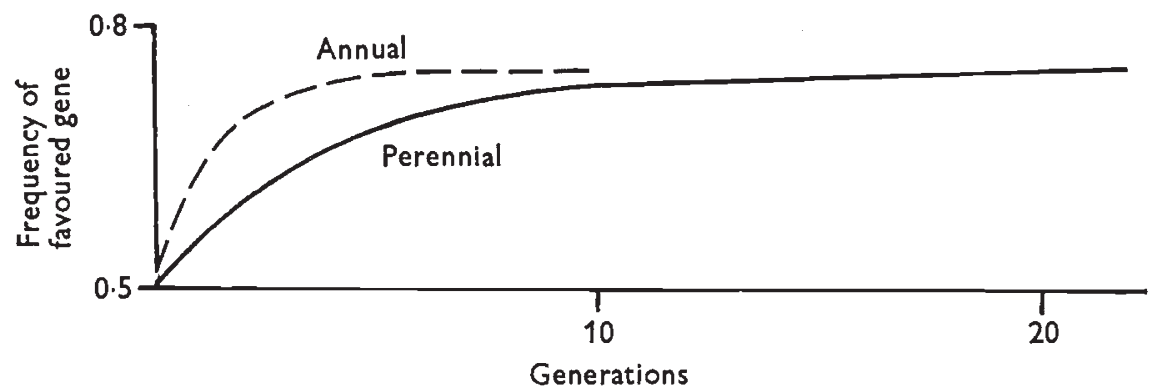

(b) Effect of perenniality on heterozygosity. (population and gene flow as above, initial gene frequencies $=0.5$ and 0.1 ).

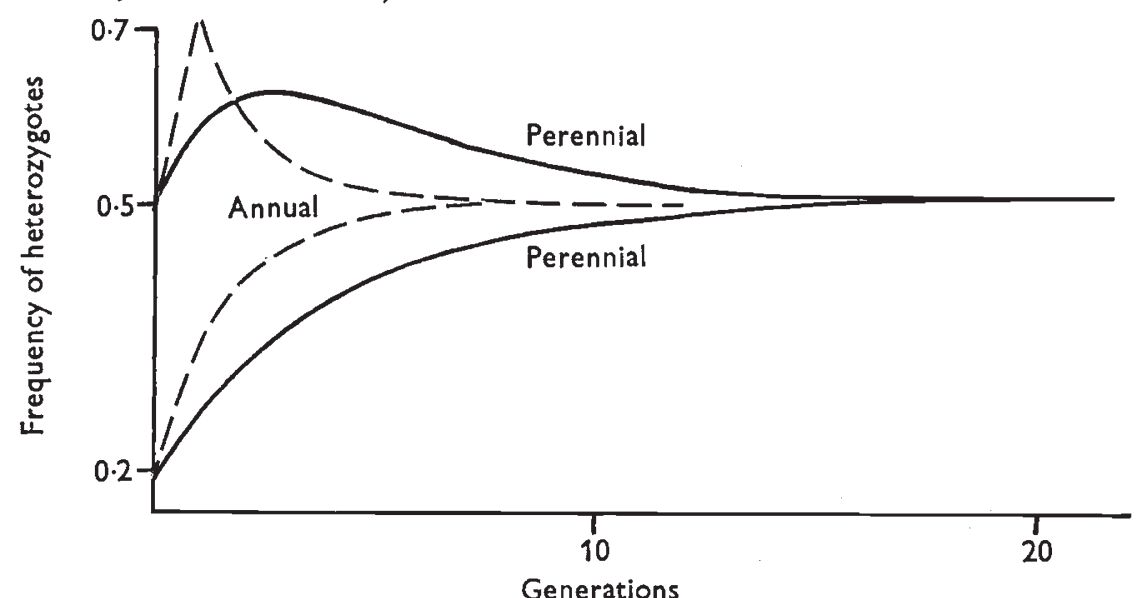

Fig. 5.-Effect of selection and pollen flow on gene frequency and heterozygosity in perennial and annual populations. (Selection coefficients $=1 \cdot 0$, pollen flow $=0 \cdot 2$, favoured gene is dominant.)

\section{(e) Pollen flow load}

The degree of mortality suffered by the population as a result of the introduction of unadapted types by pollen flow was calculated (see Antonovics, 1967a). The results (fig. 6) show that pollen flow load is less the higher the 
frequency of the favoured gene, the greater the degree of dominance of the favoured gene, the lower the selection pressure, and the lower the pollen flow.

TABLE 1

Number of generations to equilibrium with different initial gene frequencies and different amounts of pollen flow. (Selection coefficient $=0.4$, dominance of favoured gene)

\begin{tabular}{|c|c|c|c|c|}
\hline \multirow[b]{2}{*}{$\begin{array}{c}\text { Pollen } \\
\text { flow }\end{array}$} & \multicolumn{4}{|c|}{ Initial frequency } \\
\hline & $0 \cdot 01$ & $0 \cdot 1$ & 0.5 & 0.9 \\
\hline 0 & 501 & 501 & 501 & 501 \\
\hline $0 \cdot 1$ & 63 & 58 & 50 & 51 \\
\hline $0 \cdot 2$ & 57 & 50 & 38 & 45 \\
\hline $0 \cdot 3$ & 57 & 49 & 37 & 45 \\
\hline $0 \cdot 4$ & 61 & 52 & 44 & 48 \\
\hline 0.5 & 71 & 58 & 52 & 55 \\
\hline $0 \cdot 6$ & 90 & 70 & 69 & 71 \\
\hline $0 \cdot 7$ & 143 & 63 & 113 & 115 \\
\hline $0 \cdot 8$ & 501 & 501 & 501 & 501 \\
\hline $0 \cdot 9$ & 78 & 98 & 104 & 106 \\
\hline $1 \cdot 0$ & 42 & 53 & 58 & 58 \\
\hline
\end{tabular}

\section{(f) Discussion}

One of the most remarkable features to emerge from this computer simulation is the effectiveness of gene flow in determining the genetic structure of populations. This effectiveness is a reflection of the former belief that differentiation over short distances is impossible (Mayr, 1947).

Gene flow can, if it is sufficiently strong and if selection against the incoming genes is weak, completely obliterate the favoured gene. Even where selection is strong and gene flow weak, the incoming genes are maintained in the population: gene flow can lead to a polymorphic situation. The pattern of pollen distribution is leptokurtic, and this implies that an appreciable amount of pollen travels long distances (see Jain and Bradshaw, 1966, for discussion). This background "rain" of pollen is probably a very important factor in dispersing genes over wide distances and the present work shows that these genes will be maintained in the populations at a higher frequency than the pollen flow itself.

The presence of unadapted genes produces a gene flow load on the population. This may affect the population in two ways. Firstly, gene flow load may have ecological consequences: it may affect the rate of colonisation as this is dependent on having a sufficient supply of adapted types. This may not seem a great problem in view of the large amounts of seed that can be produced by most plants. However, if we take the example of metal tolerant populations on mine soils, even if numerous metal tolerant individuals are produced, they must, if they are to survive, carry genes adapting them also physiologically (Jowett, 1959) and morphologically (Bradshaw, 1959; Antonovics, 1966) to the mine habitats. Secondly, gene flow load may have genetic consequences : there will be constant selection for mechanisms to reduce gene flow load and increase population fitness. Previous papers in this series have considered two such mechanisms, namely differences 
in flowering time (McNeilly and Antonovics, 1967) and self-fertility (Antonovics, 1967a). Both these mechanisms seem to be operative to some extent in mine populations.

\section{Favoured gene no.dominance Favoured gene dominant}

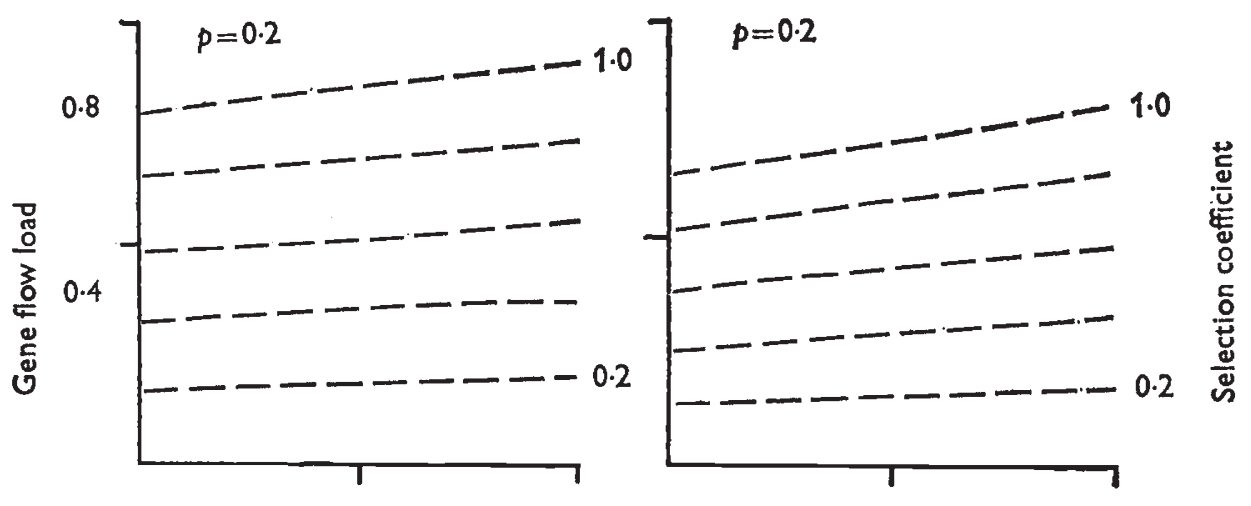

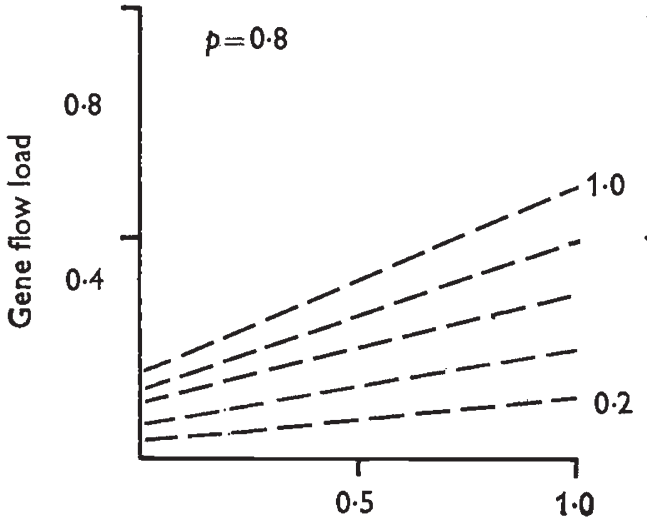

Pollen flow

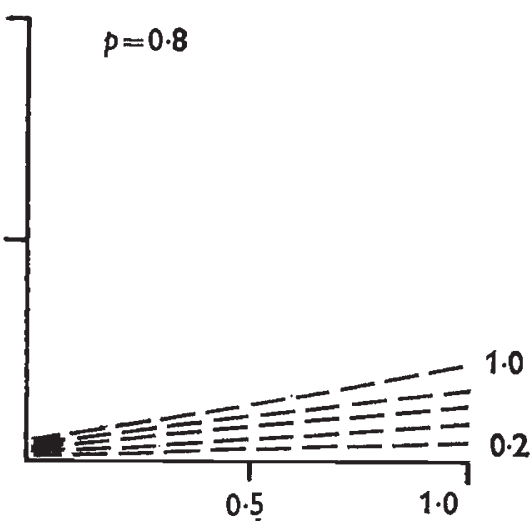

Pollen flow

FIG. 6.-Effect of selection and pollen flow on genetic load of a population at various, not necessarily equilibrium, frequencies, $p$, of the favoured gene. (Selection coefficient, gene frequencies and degree of dominance of favoured gene are indicated on graphs.)

Gene flow is important also as a means of preserving heterozygosity. Even with very little pollen flow the proportion of heterozygotes in the population is above random expectations, particularly so when the incoming genes are recessive. Strong selection against them increases the proportion that are heterozygous, since incoming genes are sheltered in the heterozygous state.

The results of this computer investigation can be applied to the situation existing in mine populations which suffer from pollen flow from adjacent pasture populations. Here selection for tolerance is powerful (McNeilly and Bradshaw, 1967; McNeilly, 1967) and all the evidence points to metal 
tolerance being dominant or partly so (Wilkins, 1960; Broker, 1963; Gries, 1966; Antonovics, 1966). On this basis we can predict that mine populations should be in equilibrium in terms of gene flow and selection, since with high selection, gene flow, and dominance, equilibrium is reached rapidly. A similar conclusion was reached by Jain and Bradshaw (1966). Moreover, we should expect mine populations to consist of highly heterozygous individuals. This idea is supported by the amount of segregation observed in $F_{1}$ crosses between tolerant and non-tolerant plants (Wilkins, 1960; Antonovics, 1966) and in seedlings from mine populations (McNeilly and Bradshaw, 1967; McNeilly, 1967). The extreme heterozygosity of the individuals in the initial stages of colonisation may help to explain why mine populations have a greater self-fertility than pasture populations. Even fairly high degrees of self-fertility do not reduce the heterozygote frequency below random expectation when gene flow is present (fig. 7). Another prediction that could be made from the computer investigation is that we should expect mine populations to be more perennial than pasture populations. Although mine populations do show population turnover (Antonovics, $1967 b)$, comparative studies of mine and pasture populations have not been done. However, it is relevant to note that very few annual species are found in mine habitats. On highly contaminated areas they are completely absent. In general, the problem of perenniality is ecological as well as genetical: with perenniality each generation does not have to be established de novo and colonisation is quicker in that the members of every generation are added to those of the next.

It is seen that gene flow has manifold effects on natural populations both in theory and most probably in practice; it is surprising that it has been neglected as an evolutionary factor for so long.

\section{The Evolution of Dominange}

\section{(a) Introduction}

It has been shown in the previous section that gene flow load on a population is less if the favoured gene is dominant, and that under conditions of pollen flow and selection there is a very large proportion of heterozygotes in the population. One of the main objections (Crosby, 1963) against the idea that dominance can be evolved is the low frequency in natural populations of heterozygotes on which modifiers can act. Polymorphism also maintains heterozygotes in a population and dominance modification is well known here (Sheppard and Ford, 1966).

The computer model was therefore modified to investigate if the evolution of dominance could be another consequence of gene flow.

\section{(b) The model}

A second gene was added to the previous model to give a simple two gene situation. One gene was considered to be the dominance modifier of the other gene subjected and unlinked to the modifier. The dominance relations of the selected gene were changed according to which modifier genotype was present. For example, the fitness of different genotypes with and without the modifier are indicated below (when the modifier itself shows no dominance). 

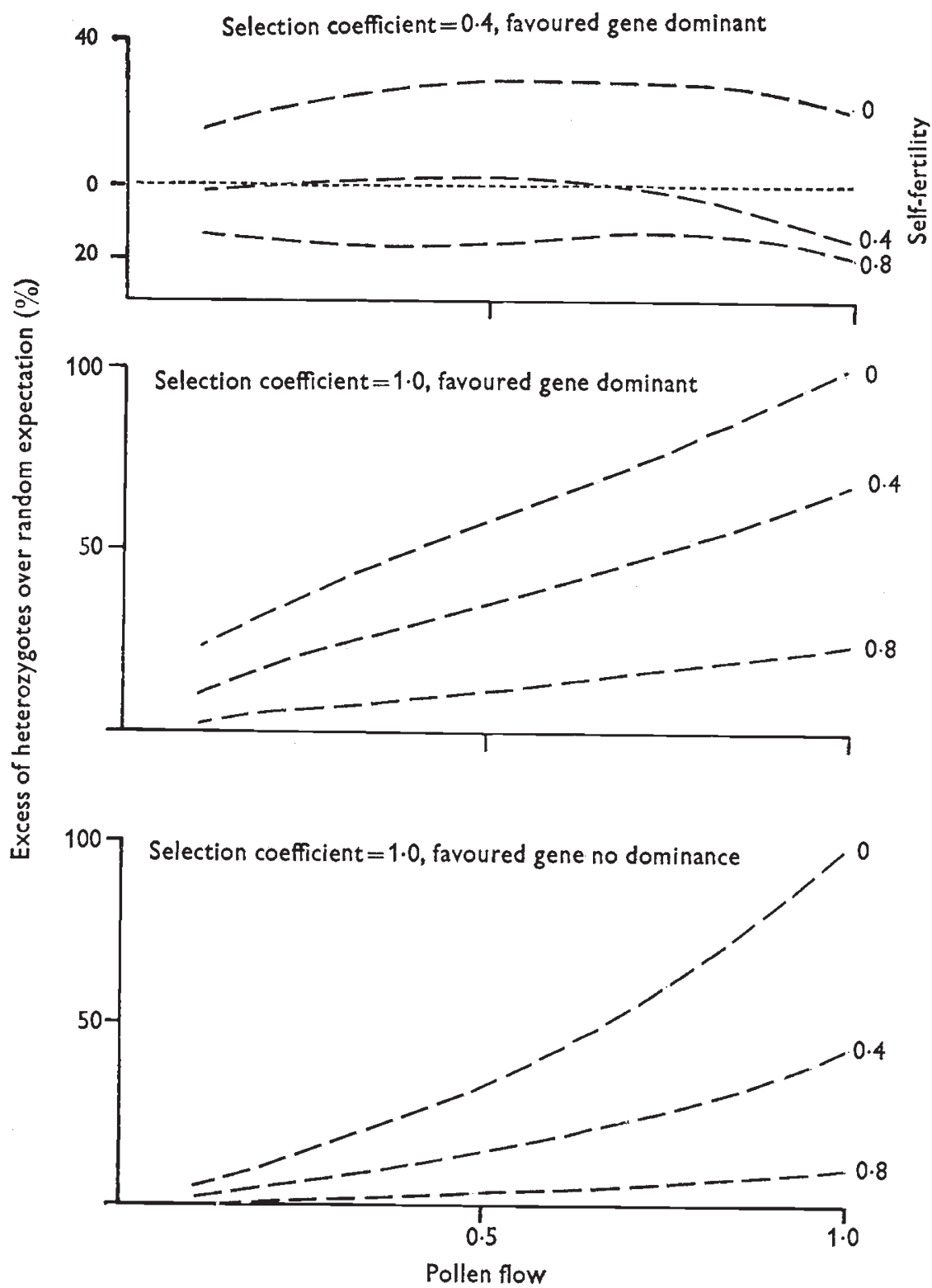

FIG. 7.-Effect of self-fertility on heterozygosity at equilibrium with different amounts of selection and pollen flow. (Self-fertility, selection coefficients, degree of dominance of favoured gene are indicated on graphs. Selfing gene has no dominance and is completely linked to the favoured gene.) 
Genotype selected

\begin{tabular}{|c|c|c|c|c|c|}
\hline & & & & & \\
\hline & & $A A$ & $A a$ & $a a$ & \\
\hline & $b b$ & 1 & 0.5 & 0 & No modifier, no dominance \\
\hline Modifier & $B b$ & 1 & $0 \cdot 75$ & 0 & Partial dominance \\
\hline & $B B$ & 1 & & 0 & Full dominance \\
\hline
\end{tabular}

The population containing these two genes was subjected to gene flow and selection as before. The gene flow considered was that resulting from pollen flow.

\section{(c) Results}

The results (tables 2 and 3 ) show that the dominance modifier does not generally spread through the population to any appreciable degree in the

\section{TABLE 2}

Equilibrium frequency (per cent.) of a modifier giving dominance in a population subjected to selection and pollen flow. Number of generations to equilibrium indicated in brackets below frequency of modifier, and heavy type indicates where the frequency of the modifier is greater than that with no gene flow. (Equilibrium position chosen as point when gene frequency of modifier plus favoured gene did not change by more than 0.01 per cent.; initial freqeuncy of modifier is 1 per cent., and initial frequency of favoured gene is 50 per cent.)

Fitness of genotypes after dominance modification

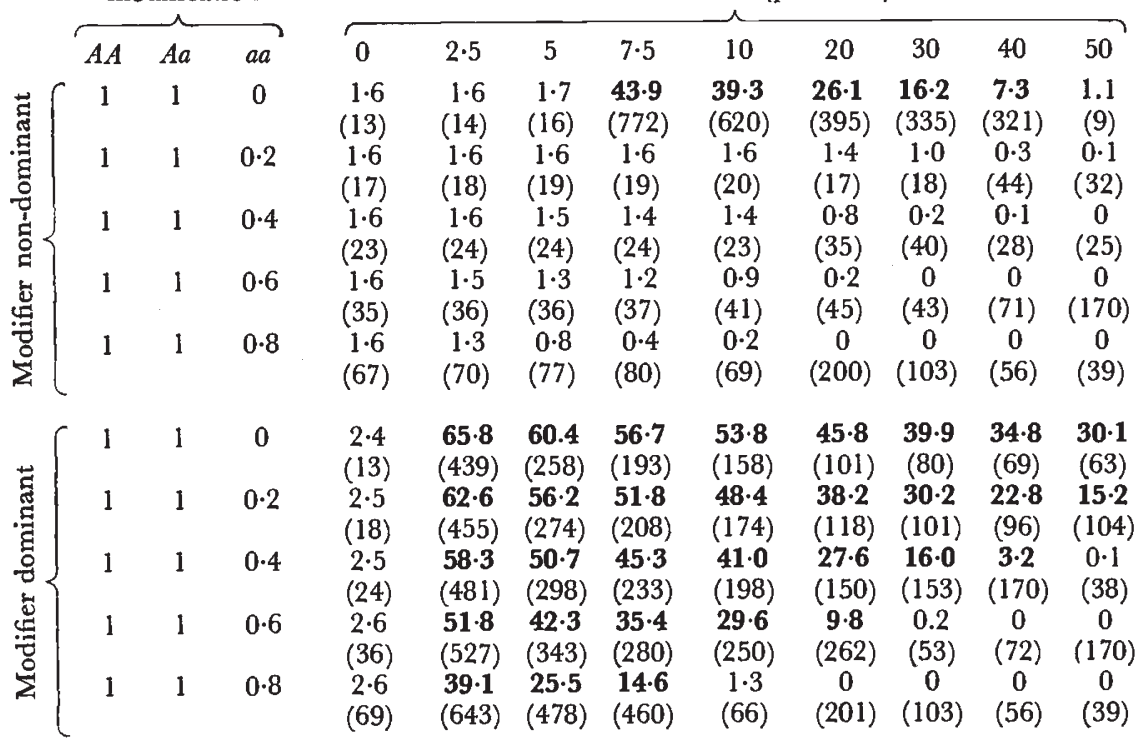

absence of pollen flow. The modifier spreads through the population without pollen flow if it imposes a considerable amount of overdominance. The reasons for this are twofold. Firstly, it is because by definition the modifier interacts with the gene on which selection is occurring and it therefore acquires a selective advantage. Secondly, an overdominance modifier, by 
virtue of its modifying action, maintains heterozygotes in the population on which further modifiers can act. Both these points are illustrated in table 4 .

In the presence of pollen flow the spread of the dominance modifier is large and rapid, and it reaches a frequency far in excess of its frequency

\section{TABLE 3}

Equilibrium frequency (per cent.) of a modifier giving overdominance in a population subjected to selection and pollen flow. Number of generations to equilibrium indicated in brackets below frequency of modifier, and heavy type indicates where the frequency of the modifier is greater than that with no gene flow (Population as in Table 2).

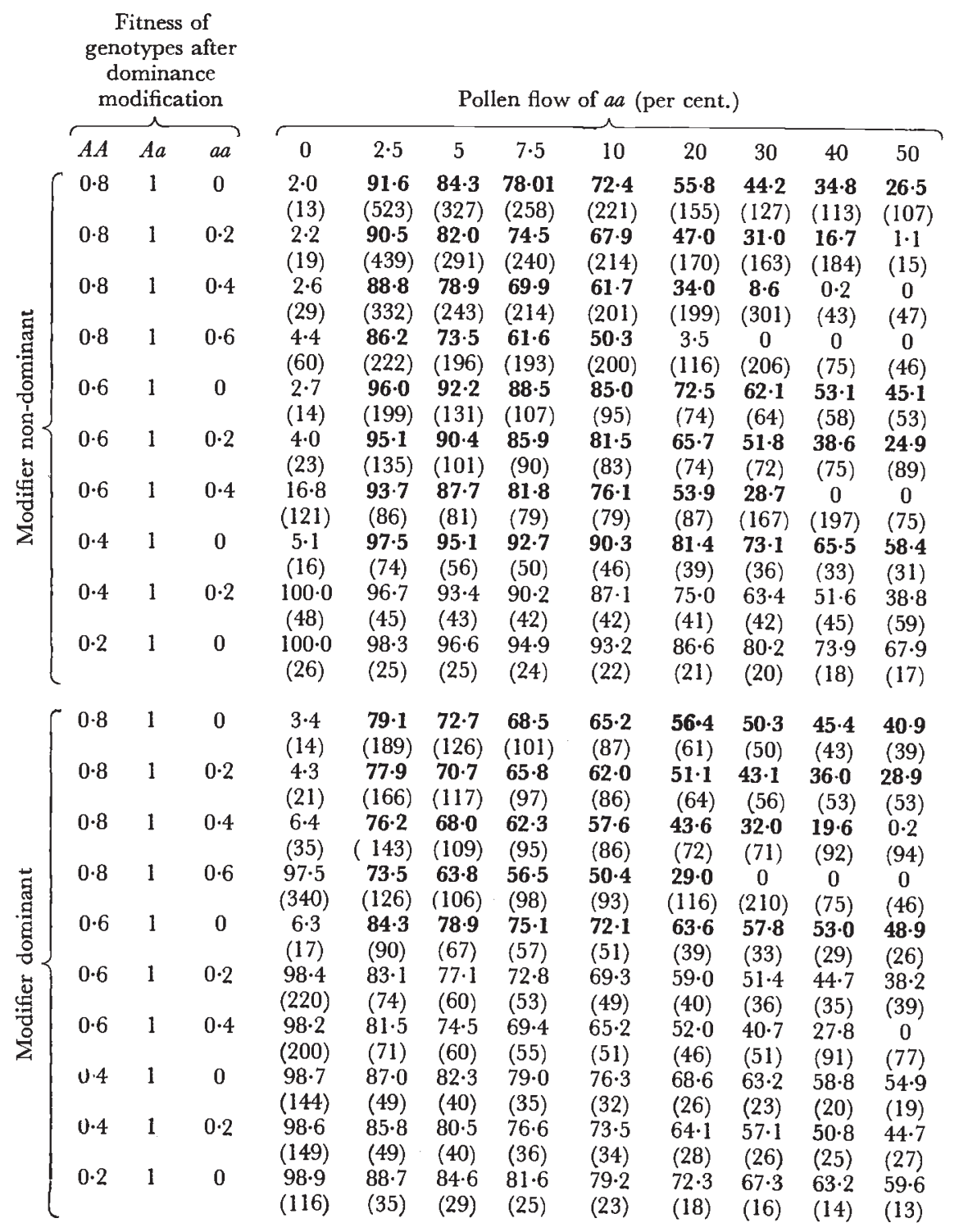


without pollen flow. Considering the general situation, the modifier reaches a higher frequency if the selection pressure is greater and if the pollen flow is lower. The effects of pollen flow are subtle: although a greater final frequency is reached with lower amounts of pollen flow, the time taken to reach equilibrium is greater. With no or very little pollen flow the favoured gene reaches fixation before the modifier has had a chance to spread appreciably through the population.

The modifier will also spread more if it is itself dominant and if the dominance modification is greater. Thus genes imposing overdominance reach a higher frequency than those imposing dominance (table 3).

\section{TABLE 4}

Examples of effect of interaction between a dominance modifier gene and the selected gene on the mean fitnesses of these genes. Frequencies of both genes $=0.5$

Modifier producing full dominance

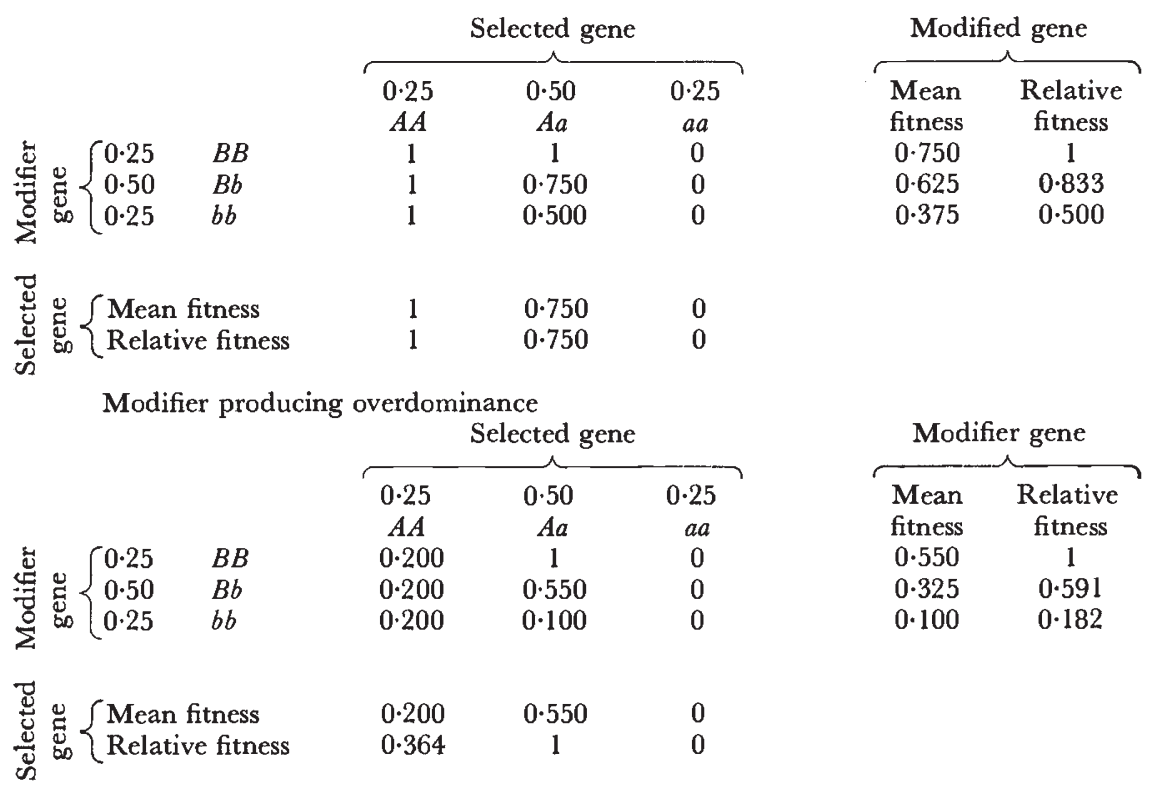

\section{(d) Discussion}

The results show that the evolution of dominance and overdominance is possible and rapid in a population subjected to pollen flow. The modifier spreads through the population even though there are non-modifier genes continually entering the population and preventing its fixation. The entry of non-modifier genes from outside leads to the situation where spread of the modifier is greater (even though it is slower) if the pollen flow is less: and it has been remarked previously that long distance transport of pollen at a low but appreciable frequency is likely to be commonplace.

The increased effectiveness of the modifier, if it is itself dominant, suggests that there will be a tendency for the modifiers themselves to become dominant, or even overdominant, whether through their preferential selection or by the action of further modifiers. Gene flow in natural populations may 
therefore have considerable repercussions on the expression and interaction of the genes involved.

Although modifiers producing extreme overdominance will spread much more readily and even in the absence of gene flow, these modifiers are likely to be rare in natural populations. If they do occur they would be fixed rapidly and the gene would appear " inherently" overdominant.

It is relevant to inquire whether there is evidence for any of these processes in natural populations. Unfortunately the genetics of characters distinguishing adjacent populations has not been studied extensively. Preliminary inves tigations on the genetics of heavy metal tolerance show that lead tolerance in Festuca ovina (Wilkins, 1960) and copper tolerance in Agrostis tenuis (Antonovics, 1966) is sometimes but not invariably dominant. This suggests that metal tolerance is not inherently dominant and that modification of dominance is possible and may be occurring.

Another corollary to these results is the expectation that a gene will show different directions of dominance at the opposite ends of a cline. Some evidence for this comes from the work of O'Donald and Davis (1959), who showed that the dark-phase in the colouration of the Arctic Skua is more dominant where it is more frequent, and vice versa for the light phase. O'Donald and Davis, however, consider that such evolution of dominance " can only occur once the population has become isolated from the migration taking place within the cline: the introduction of alien gene complexes must continually break down the modifier balance". The present data suggest that such isolation may not only be unnecessary but positively detrimental to the evolution of dominance within a cline.

The readiness with which modifiers producing overdominance will spread in a population subjected to gene flow indicates one way in which heterozygous advantage may develop for many characters in natural populations. Since no work has been directed at assessing the extent of this explanation, it can only be inferred from the heterogeneity of habitats and the populations adapted to them that this is at least in part a frequent explanation both of heterozygous advantage resulting in polymorphism (Ford, 1964, chap. 6), and of general heterozygosity in natural populations (Lewontin and Hubby, 1966).

The importance of modifier genes in natural populations has been emphasised by Clarke (1966), and the present work shows another way in which the genetic architecture of natural populations could be changed by modifiers. Not only are the dominance relations of the genes within the population altered, but since dominance reduces the gene flow load on a population it acts as another isolating mechanism between adjacent populations, in addition to flowering time and self-fertility.

\section{Conclusions}

The results presented here are largely theoretical. However, the stimulus behind them comes from the fact that gene flow is likely to be the rule and not the exception.

The evolution of distinctive populations is now a well-known phenomenon in both plants and animals. Habitats and populations form graded patchworks : wherever there are contrasting habitats there are selection pressures leading to population differentiation. Very few of these populations are 
completely isolated (or completely uniform in themselves) and gene flow between them must occur to varying degrees. This is true of artificial as well as natural populations. There is plenty of evidence that gene flow is important in crop plants. Many studies on pollen dispersal (e.g. Griffiths, 1950; Bateman, 1947) were designed primarily to study the amount of cross-contamination between different crop varieties in the same area. In the conditions of primitive agriculture under which most of our crop plants evolved it is likely that the new varieties would be grown alongside the old without any isolation (e.g. Zohary, 1960; Rick, 1958; Mangelsdorf et al., 1964). The present model is therefore relevant to many natural and seminatural situations and it alters our concepts of evolution in populations.

Evolution has generally been studied in idealised populations where gene flow has been ignored or regarded as of only trivial importance. This is dangerous, since many central problems of population genetics such as polymorphism, evolution of dominance and heterozygous advantage can be seen as possible consequences of gene flow.

\section{Summary}

1. The effects of gene flow of an unfavourable gene on a population were studied using a deterministic computer model.

2. Two types of gene flow were distinguished: in the case of pollen flow, selection occurred after mating, whereas in the case of seed flow it occurred before mating.

3. Pollen flow was extremely effective in maintaining an unfavourable gene in the population and led to an excess of heterozygotes over random expectation.

4. Seed flow was less effective than pollen flow in maintaining a gene in a population under high selection intensities against it, but more effective under low selection intensities. It did not lead to an excess of heterozygotes over random expectation.

5. The high degree of pollen flow during the early stage of colonisation drastically reduced the frequency of the favoured gene during this early stage.

6. Perennial populations changed more slowly than annual populations with regard to gene frequencies, and they could withstand the deleterious effects of pollen flow during the initial stages of colonisation better than annual populations.

7. Under conditions of pollen flow there was rapid spread of modifiers producing dominance and overdominance of the favoured gene. The evolution of dominance did not occur appreciably in the absence of pollen flow.

8. The evolution of dominance was interpreted as an isolating mechanism since it lowered the gene flow load resulting from the introduction of unfavourable genes into the population.

9. Gene flow was considered to be the rule rather than the exception in natural populations and of great importance to theories of polymorphism, evolution of dominance, and heterozygous advantage.

Acknowledgments.-I would like to thank the staff of the Computing Laboratory, University College of North Wales, for their friendly assistance, and Dr A. D. Bradshaw and Dr P. O'Donald for their help and criticism. I would also like to acknowledge the tenure of a University of Wales I.C.I. Research Fellowship during part of this work. 


\section{REFERENCES}

ANTonovics, J. 1966. The genetics and evolution of differences between closely adjacent plant populations with special references to heavy metal tolerance. Ph.D. Thesis, University of Wales.

ANTonovics, J. 1967a. Evolution in closely adjacent populations. V. The evolution of self-fertility. Heredity, 23, 219-238.

ANtonovics, J. 1967b. Quoted in HARPER, J. L. 1967. A Darwinian approach to plant ecology. F. Ecol, 55, 247-270.

Bateman, A. J. 1947. Contamination in seed crops. III. Relation with isolation distance. Heredity, 1, 303-336.

Bradshaw, A. D. 1959. Population differentiation in Agrostis tenuis Sibth. I. Morphological differentiation. New Phytol., 58, 208-227.

BRADSHAW, A. D. 1965. Evolutionary significance of phenotypic plasticity in plants. Adv. Genet., 13, 115-155.

BROKER, w. 1963. Genetisch-physiologische Untersuchungen uber die zinkvertraglichkeit von Silene inflata Sm. Flora, Jena, 153, 122-156.

CLARKE, B. 1966. The evolution of morph-ratio clines. Am. Nat., 100, 389-402.

CROSBY, J. 1963. The evolution and nature of dominance. F. Theoret. Biol., 5, 35-51.

FORD, E. в. 1964. Ecological Genetics. Methuen, London.

GRIES, B. 1966. Zellphysiologische Untersuchungen uber die zinkresistenz bei Galmeioekotypen und Normalformen von Silene cucubalis Wib. Flora, Jena, 156, 271-290.

GRIFFITHS, D. J. 1950. The liability of seed crops of perennial rye grass (Lolium perenne) to contamination by wind-borne pollen. F. Agri. Sci., 40, 19-38.

JAIN, s. K., AND BRADSHAW. A. D. 1966. Evolutionary divergence among adjacent plant populations. I. The evidence and its theoretical analysis. Heredity, 21, 407-441.

JOWETT, D. 1959. Adaptation of a lead-tolerant population of Agrostis tenuis to low soil fertility. Nature, 184,43 .

LEVINS, R. 1965. Theory of fitness in a heterogeneous environment. V. Optimal genetic systems. Genetics, 52, 891-904.

LEwontin, R. C., AND HUBBy, J. L. 1966. A molecular approach to the study of genic heterozygosity in natural populations. II. Amount of variation and degree of heterozygosity in natural populations of Drosophila pseudoobscura. Genetics, 54, 595-609.

MANGELSDORF, P. C., MACNEISH, R. S., AND GALINAT, w. c. 1964. Domestication of corn. Science, $143,538-545$.

MAYR, E. 1947. Ecological factors in speciation. Evolution, 1, 263-288.

MCNEILLY, T. 1967. Evolution in closely adjacent populations. III. Agrostis tenuis on a small copper mine. Heredity, 23, 99-108.

MGNEILly, T., AND ANTONOvics, J. 1967. Evolution in closely adjacent populations. IV. Barriers to gene flow. Heredity, 23, 205-218.

MCNEILly, T., AND BRADShAW, A. D. 1968. Evolutionary studies on copper tolerant Agrostis tenuis. Evolution. (In press.)

o'Donald, P., AND DAvis, P. E. 1959. The genetics of the colour phases of the Arctic Skua. Heredity, 13, 481-486.

RICK, с. M. 1958. The role of natural hybridisation in the derivation of cultivated tomatoes of Western South America. Econ. Bot., 12, 346-467.

SHEPPARD, P. M., AND FORD, E. B. 1966. Natural selection and the evolution of dominance. Heredity, 21, 139-147.

WILKINs, D. A. 1960. The measurement and genetical analysis of lead tolerance in Festuca ovina. Rep. Scott. Pl. Breed. Stn., 1960, 85-98.

zohary, D. 1960. Studies on the origin of cultivated barley. Bull. Res. Course Israel, 9D, 21-42. 